\title{
An Evaluation of Pixel-based and Object-based Classification Methods for Land Use Land Cover Analysis Using Geoinformatic Techniques
}

\begin{abstract}
Land use land cover (LULC) classification is a valuable asset for resource managers; in many fields of study, it has become essential to monitor LULC at different scales. As a result, the primary goal of this work is to compare and contrast the performance of pixel-based and object-based categorization algorithms. The supervised maximum likelihood classifier (MLC) technique was employed in pixel-based classification, while multi-resolution segmentation and the standard nearest neighbor (SNN) algorithm were employed in object-based classification. For the urban and suburban parts of Kolhapur, the Resourcesat-2 LISS-IV image was used, and the entire research region was classified into five LULC groups. The performance of the two approaches was examined by comparing the classification results. For accuracy evaluation, the ground truth data was used, and confusion matrixes were generated. The overall accuracy of the object-based methodology was $84.66 \%$, which was significantly greater than the overall accuracy of the pixel-based categorization methodology, which was $72.66 \%$. The findings of this study show that object-based classification is more appropriate for high-resolution Resourcesat-2 satellite data than MLC of pixel-based classification.
\end{abstract}

Keywords: pixel-based classification (PBC), object-based classification (OBC), maximum likelihood classifier, multi-resolution segmentation

Received: 8 July 2021; accepted: 13 January 2022

(C) 2022 Authors. This is an open access publication, which can be used, distributed and reproduced in any medium according to the Creative Commons CC-BY 4.0 License.

1 Shivaji University, Department of Geography, Kolhapur, Maharashtra, India, email: sudhirpowar100@gmail.com, (D) https://orcid.org/0000-0003-4591-3084

2 Shivaji University, Department of Geography, Kolhapur, Maharashtra, India

3 Shivaji University, Department of Geography, Kolhapur, Maharashtra, India, (D) https://orcid.org/0000-0003-1985-0921 


\section{Introduction}

Land use and land cover (LULC) analysis is significant for land resource policy, land management, and land system analysis [1]. LULC is essential component of understanding the relationships between human activities and the environment [2]. The LULC data provides a panoramic view of the landscape's characteristics and facilitates decision-making on interconnected parts of most land-based processes [3]. It can be obtained from satellite images using remote sensing image classification [4,5]. Most LULC classifications have traditionally been based on the pixel-based classification (PBC) of remotely sensed images. They utilized supervised or unsupervised classification, or a combination of both [6]. Maximum likelihood classification (MLC) is one of the classification techniques of pixel-based image classification. It was observed that per-pixel MLC was restricted since it only used spectral information and does not include texture or contextual information into consideration $[7,8]$. It was also found that when pixel-based methods were applied to high-resolution images, a "salt and pepper" noise was created, which added to the inaccuracy of the classification [9-11].

To overcome such problems, remote-sensed image analysis is increasingly employing classification based on objects (segments) rather than single pixels [12]. Object-based classification $(\mathrm{OBC})$ is based on image segmentation and the formation of a hierarchical network of homogeneous objects that corresponds to feature boundaries. This segmentation process uses a variety of data types throughout the image, including pixel values, contextual information, object features, and hierarchy relationships [13].This modern approach has gained popularity in remote sensing over the last decade [14]. Several studies have already shown the applicability of OBC (frequently also referred to as Geographic Object-Based Image Analysis or GEOBIA) to LULC mapping using knowledge-based methods as well as quantitative methods [15-18]. Many computer software packages for OBC have been developed, such as eCognition $\AA$.

In the present study, LULC mapping was performed using PBC and OBC of high-resolution images (Resourcesat-2). The five LULC categories were identified as agriculture land, barren land, built-up area, forest area, and waterbody. The outcomes were compared in a statistically rigorous manner. The major focus of this research is to identify LULC classes using pixel-based and object-based image classification and to compare the accuracy of the two classification methods.

\section{Study Area}

The entire study area is extended between $16^{\circ} 37^{\prime}$ to $16^{\circ} 48^{\prime}$ North latitude and $74^{\circ} 10^{\prime}$ to $74^{\circ} 18^{\prime}$ East longitude. The total area of the study is $169.58 \mathrm{~km}^{2}$, including Kolhapur city urban and surrounding suburban areas. The Panchaganga River is 
flowing through the north side of the study area, This river is a tributary of the $\mathrm{Kr}$ ishna. The elevation of the study region is $546 \mathrm{~m}$ above sea level and has a moderate climate with a min temperature of $15^{\circ} \mathrm{C}$ and a max $40^{\circ} \mathrm{C}$ and receives an average rainfall of $1043 \mathrm{~mm}$. It has a unique physiographic setup with gentle slope decreases to the north from the south.

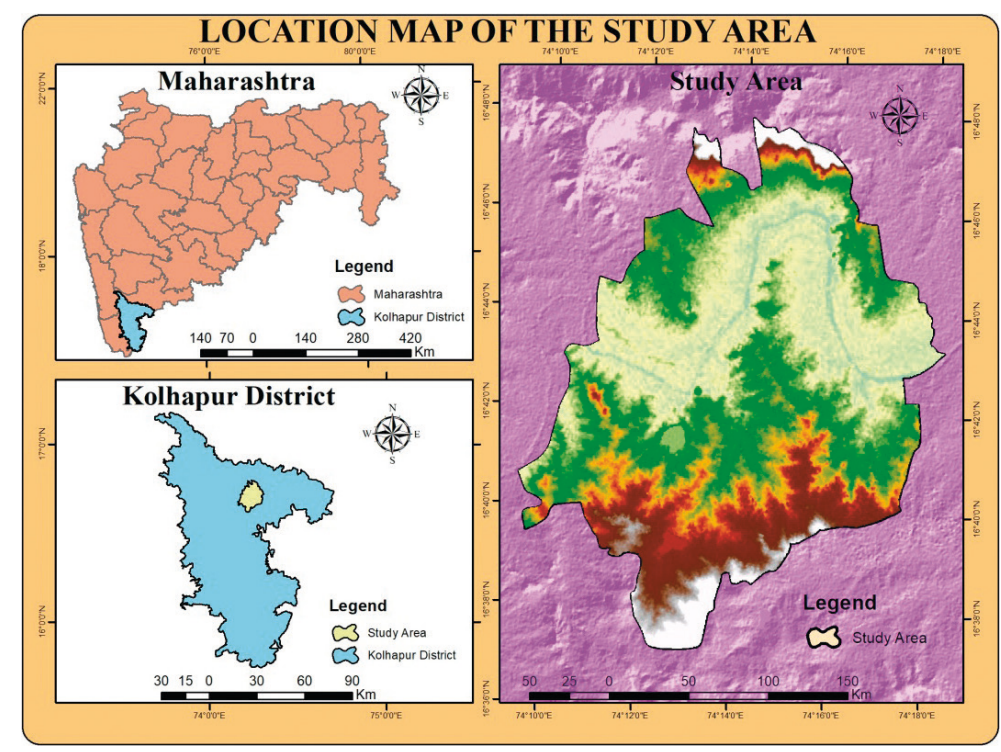

Fig. 1. Location map of the study area

\section{Database and Methodology}

\subsection{Database}

For this research, Resourcesat-2 (LISS IV) data was acquired with a spatial resolution of $5.8 \mathrm{~m}$ and three (green, red, NIR) spectral bands were used. One vector boundary of the study area was acquired by the Municipal Corporation of the city. GPS (Global Positioning System) was used for collecting Ground Control Points (GCPs), and these GCPs were used as ground truth information for the classified images. For pixel-based and object-based classification, the built-in functions of Erdas Imagine and eCognition software (Definiens Imaging, Germany) were used. Also, ArcGIS software was used for the comparative study of classified images, accuracy assessment, etc.

\subsection{Methodology}

The LISS-IV image was geo-referenced to UTM zone 43 using spheroid and datum in WGS-84 and geometrically adjusted with ground truth data. Because there 
was no visible haze or clouds in the image, and the data quality was deemed appropriate for classification, no atmospheric adjustment was applied. Figure 2 depicts the overall methodology, while the individual procedures are given further below.

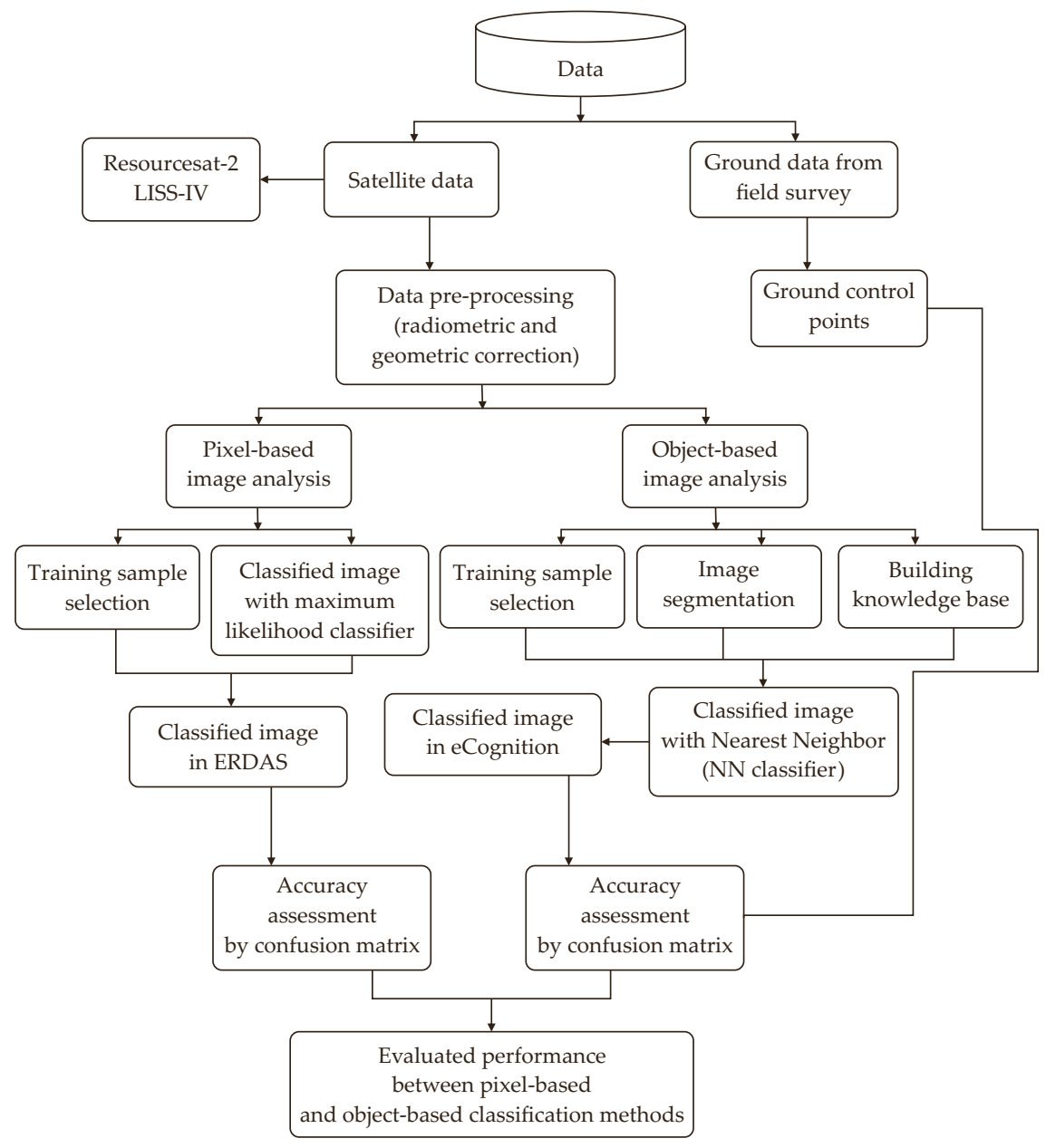

Fig. 2. Research methodology

\section{A Pixel-based Classification Method}

Pixel-based supervised image classification determines the class of each pixel in the imagery by comparing the pixel's $n$-dimensional data vector to the model vector for each class. Typically, data vectors are made up of pixels with grey level values from multispectral channels $[5,19]$. The last one (MLC) is the most generally used approach for PBC of the expected methods of classifying multispectral imagery, viz. parallelepiped, minimum distance to mean, and maximum likelihood 
classifier (MLC). The maximum likelihood (ML) classifier supervised classification algorithm was employed in this investigation. The training data is used to estimate the probabilities [20] that a pixel belongs to a certain class which based on a subsequent probability of membership and dimensions equal to numerous bands in the source image [3]. The training signatures (pixels) for each class were chosen to represent the majority of the class's spectral characteristics over the entire image. The MLC assigns a pixel to the class with the highest probability of membership, where $L_{i}(x)$ is the chance that pixel $x$ is a member of class $i$ is given by Equation (1):

$$
L_{i}(x)=(2 \pi)^{-n / 2}\left|V_{i}\right|^{-1 / 2} e^{-y / 2}
$$

where:

$$
\begin{aligned}
& V_{i} \text { - the class } i \text { covariance matrix, } \\
& n \text { - the number of spectral bands, } \\
& y \text { - the Mahalanobis distance. }
\end{aligned}
$$

The MLC a posteriori probability $P_{i}(x)$ is obtained by rescaling $L_{i}(x)$ between 0 and $1[5,21]$. The ERDAS Imagine software was used to achieve this pixel-based supervised maximum likelihood image categorization.

\section{Object-based Classification Method}

The object-based technique takes into account shape, texture, and spectral information. Its classification section begins with the crucial first step of grouping neighboring pixels into important areas, which may then be used in the classification phase after that [22]. Although OBC may not deal directly with single pixels, it can be used to create homogeneous image objects through the segmentation process. Image segmentation is defined as the identification for homogeneous features in an image and the subsequent classification of these regions in remote sensing [23]. There are two sorts of segmentation principles: top-down and bottom-up. Topdown segmentation involves breaking a large region into smaller pieces, whereas bottom-up segmentation involves integrating smaller items into bigger ones.

The LISS-IV image was segmented into four levels for this investigation utilizing a bottom-up strategy of the multi-resolution segmentation technique. Table 1 lists the specification segmentation criteria. The scale parameter was adjusted to 10 with a 0.1 shape parameter, and compactness was set to 0.5 in the level one segmentation criterion shown in the table. The size of objects is indirectly determined by this scale parameter; if the scale value is kept large, the object will become enormous as well. The color of the objects is determined by the Shape criterion, while the smoothness of the objects is determined by compactness. In level 2, more weight is given to scale and shape, and compactness criterion value was kept as it is like level 1 . The scale parameter was increased to 25 and 30, respectively, but the shape and compactness parameters were preserved at 0.2 and 0.7 . The result of segmentation is shown in Figure 3. 
Table 1. Segmentation criterion

\begin{tabular}{|c|c|c|c|}
\hline Level & Scale parameter & Shape & Compactness \\
\hline \hline 1 & 10 & 0.1 & 0.5 \\
\hline 2 & 20 & 0.1 & 0.5 \\
\hline 3 & 25 & 0.2 & 0.7 \\
\hline 4 & 30 & 0.2 & 0.7 \\
\hline
\end{tabular}

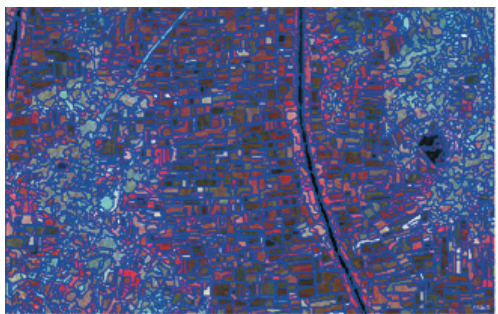

Level 1

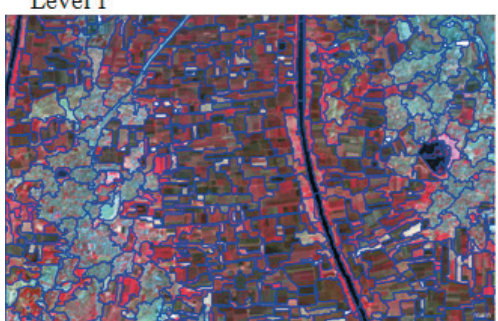

Level 3

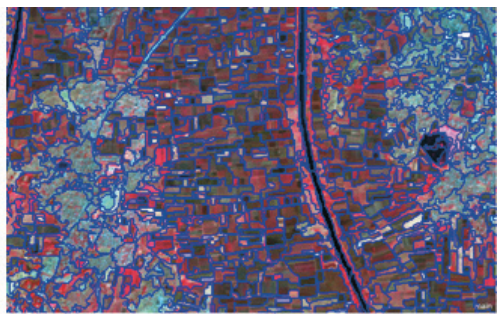

Level 2

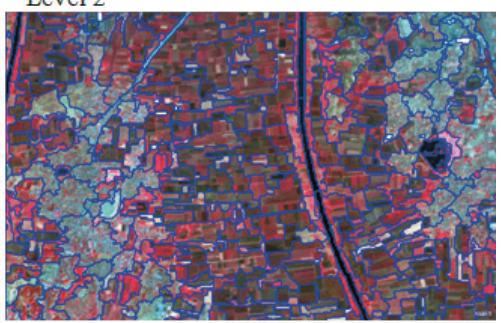

Level 4

Fig. 3. Four separate segmentation criteria used in image segmentation

Figure 3 indicates that increasing the scale parameter in the segmentation technique (from level 1 to level 4) automatically the size of segmented objects also increased in the image, and vice versa. In this segmentation procedure, prior to the segmentation method, it is impossible to determine which scale parameter is optimal. As a result, image segmentation with a distinct set of scale parameters is required, and the appropriate scale parameter for final image classification should be chosen based on the study's purpose and basic knowledge of the study area. So, for final image classification on the basis of visual observation of study area and knowledge-based approach level, two criteria (Tab. 1) were used. The next stage is to classify the segmented image into different land use/land cover classes after it has been segmented. Five LULC classes were produced through the class hierarchy process (Fig. 4b). In a hierarchically structured form, the class hierarchy process includes all classes of categorization cogitation. The inheritance classes specified in parent classes are passed to their child classes at the bottom. The inheritance hierarchy is used in the class description to reduce repetition and complication [22]. 
When preparing the hierarchy of class with their inheritance hierarchy, ground observation was used and the sample objects for each class identified. Then, for each of the classification cogitation's classes, a class description, i.e., standard nearest neighbor (SNN), was picked, which consists of a fuzzy expression that allows the evaluation of a specific feature and its reasonable operation, as well as classifying the image. Figure 4a depicts an example of an agriculture class. The segmentation technique is based not just on particular pixel values, but also on pixel spatial continuity, which includes textures and structure. The OBC was carried out with eCognition, a user-friendly, multi-scaled, and extremely useful object-based processing software [5, 24].

a)

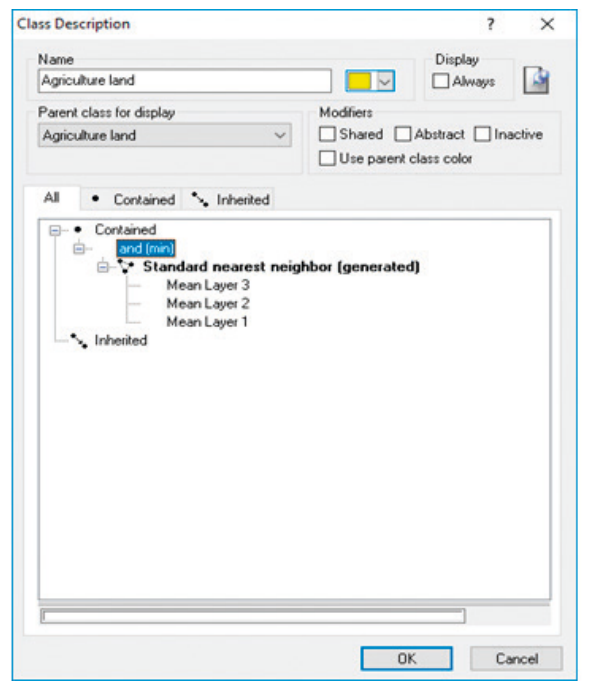

b)

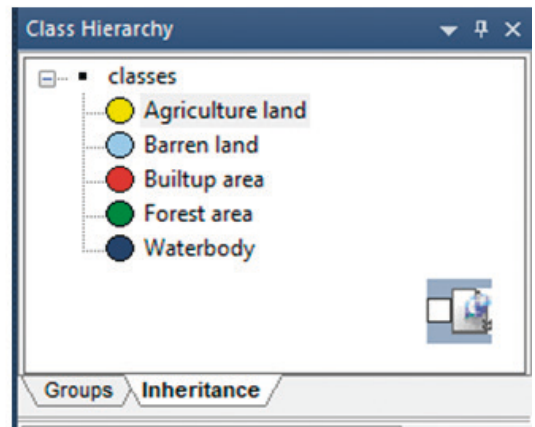

Fig. 4. Description of class (a) and hierarchy of class (b)

\section{Accuracy Evaluation}

Accuracy evaluation is an important aspect of image classification since it allows one to track the evolution and quality of the image you've classified. Valid information is needed to analyze the accuracy assessment. The term "ground truth" or "reference data" is used to describe this form of a valid dataset [25]. As a result, 150 ground truth points for each class were collected across the study region using the stratified sampling method for validation.

Two statistical accuracy evaluation approaches were used for this study: kappa analysis and a confusion matrix. Three accuracy measures are reported in the confusion matrix: producer accuracy, user accuracy, and total accuracy [26]. A twodimensional contingency table is known as a confusion matrix. It displays the cell entries in the confusion matrix together with the number of sampled points, with the row label indicating the category in the classified image and the column label indicating the ground facts. The diagonal values represent correct classifications, while 
the off-diagonal values represent incorrect classifications. Kappa analysis, which assesses the agreement between the classified image and correct values, is the second method. The kappa value ranges from 0 to 1 ; a value of 1 indicates strong agreement, while a value of 0 signifies no agreement. The user's accuracy shows the likelihood that a pixel classified into a specific category on the ground accurately represents that category. Overall accuracy refers to the likelihood that a pixel in a classed image is correctly classified.

Using the existing accuracy assessment features in the relevant software packages, the accuracy of both classifications were assessed in eCognition, ERDAS imagine, and ArcGIS. Finally, the computed confusion matrixes were used to evaluate the performance of accuracy between both (pixel and object) image classifications.

The kappa coefficient equation is shown below:

$$
K=\frac{N \sum_{i=1}^{r} x i i-\sum_{i=1}^{r}[x i \cdot(x+i)]}{N^{2}-\sum_{i=1}^{r}[x i \cdot(x+i)]}
$$

where:

$$
\begin{aligned}
& K-\text { KHAT statistic, } \\
& x i i-\text { the diagonal value of both row } i \text { and column } i, \\
& x i-\text { total of row } i \\
& x+i-\text { total of column } i \\
& N-\text { the all observations, } \\
& r-\text { the actual size of the matrix. }
\end{aligned}
$$

\section{Result and Discussion}

On the LISS-IV image, a PBC with a maximum likelihood classifier was done, as well as an OBC with the nearest neighbor classifier. Figures 5 and 6 depict the categorization findings, while Table 2 lists the classification statistics.

The categorization results of pixel-based and object-based approaches differ in a number of ways, as shown in Table 2. The area under agriculture was $36.09 \%$ of the overall area in the PBC, whereas the OBC identified $40.47 \%$ of the area under agricultural land. The same table also shows in the $\mathrm{PBC}$, the area under built-up land was $34.80 \%$ of the total area, while in the OBC, it was $32.69 \%$ of the entire area. Based on this finding, it can be stated that the pixel-based classifier simply examined spectrum values in classification rules, whereas the object-based classifier took into account spectral values, smoothness, shape, texture, and fuzzy classification logic. A comparison of Figures 5 and 6 shows that pixel-based images exhibit significant classification noise (salt and pepper noise), making it difficult to identify the LULC feature in-depth. The categorized image obtained via OBC, on the other hand, produces a more consistent categorization that is easier to interpret by human visual interpretation. 


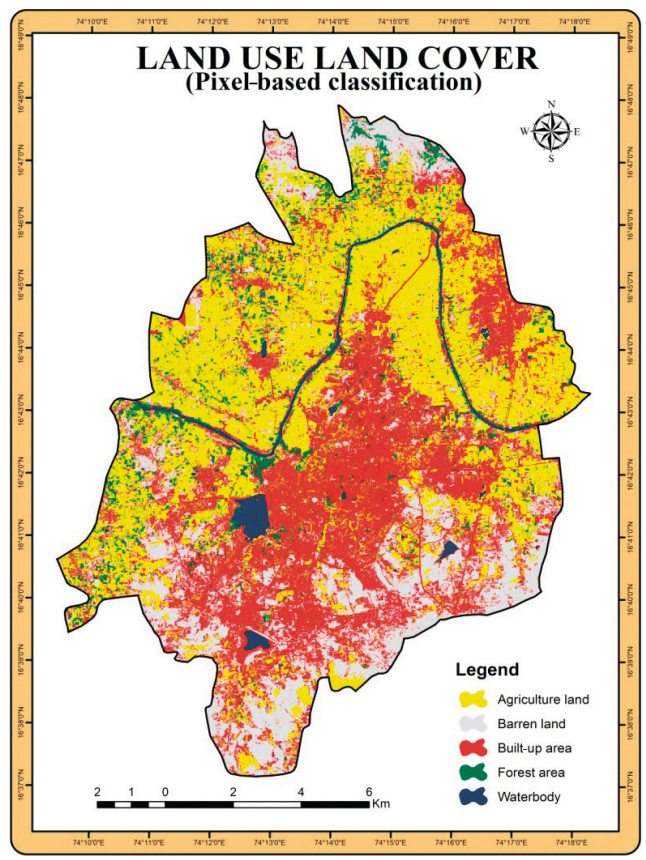

Fig. 5. Classification of LU/LC based on pixel

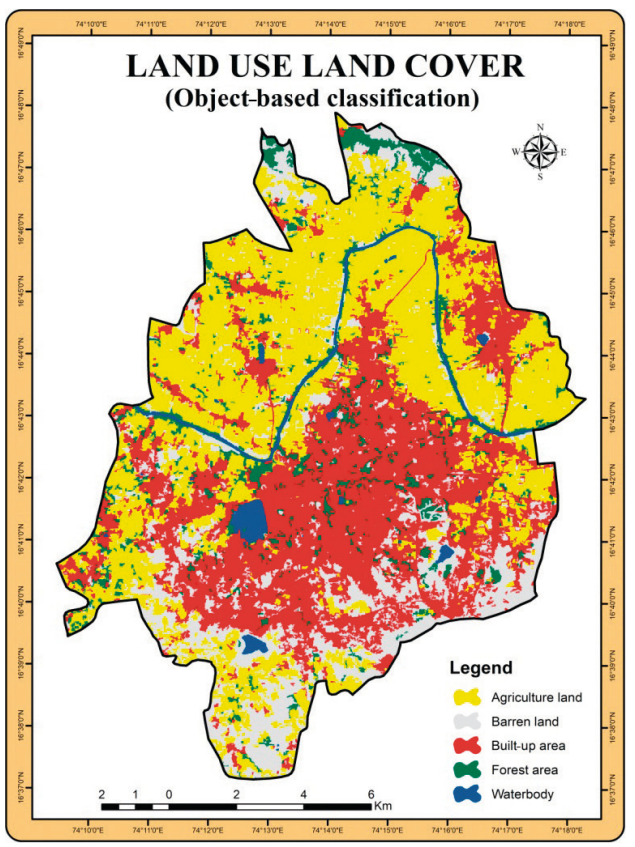

Fig. 6. Classification of LU/LC based on object 
Table 2. Spatial extent of LU/LC classification

\begin{tabular}{||l|c|c|c|c|c||}
\hline \multirow{2}{*}{$\begin{array}{c}\text { Land use/ Land cover } \\
\text { classification }\end{array}$} & \multicolumn{2}{|c|}{ Pixel-based classification } & \multicolumn{2}{|c|}{$\begin{array}{c}\text { Object-based } \\
\text { classification }\end{array}$} & \multirow{2}{*}{$\begin{array}{c}\text { Deviation from } \\
\text { object-based } \\
\text { classification [\%] }\end{array}$} \\
\cline { 2 - 5 } & $\begin{array}{c}\text { Area } \\
{\left[\mathrm{km}^{2}\right]}\end{array}$ & $\begin{array}{c}\text { Area } \\
{[\%]}\end{array}$ & $\begin{array}{c}\text { Area } \\
{\left[\mathrm{km}^{2}\right]}\end{array}$ & $\begin{array}{c}\text { Area } \\
{[\%]}\end{array}$ & -4.38 \\
\hline Agriculture land & 61.21 & 36.09 & 68.64 & 40.47 & 3.59 \\
\hline Barren land & 37.17 & 21.91 & 31.07 & 18.32 & 2.10 \\
\hline Built-up area & 59.02 & 34.80 & 55.45 & 32.69 & -1.02 \\
\hline Forest area & 9.44 & 5.56 & 11.18 & 6.59 & -0.29 \\
\hline Waterbody & 2.74 & 1.61 & 3.24 & 1.91 & - \\
\hline Total & 169.58 & 100.00 & 169.58 & 100.00 & \\
\hline
\end{tabular}

Object-based classification produces superior results than pixel-based classification, as per the examination of the final output of the two classification systems. Therefore, in order to compare these two methods more thoroughly, the confusion matrix and kappa statistics were used to assess accuracy.

\section{Accuracy Assessment}

Overall, an accuracy evaluation was carried out to compare the performance of two categorization systems. As mentioned in the methodology section, 150 sample ground control points were collected to perform the accuracy of classified images, and confusion matrixes were produced. Tables 3 and 4 shows the confusion matrixes of both classifications (pixel and object).

Table 3. Pixel-based classification confusion matrix

\begin{tabular}{|c|c|c|c|c|c|c|c|}
\hline \multirow[b]{2}{*}{ Classified data } & \multicolumn{7}{|c|}{ Reference data } \\
\hline & $\begin{array}{l}\text { Agriculture } \\
\text { land }\end{array}$ & $\begin{array}{c}\text { Barren } \\
\text { land }\end{array}$ & $\begin{array}{l}\text { Built-up } \\
\text { area }\end{array}$ & $\begin{array}{c}\text { Forest } \\
\text { area }\end{array}$ & Waterbody & Total & $\begin{array}{c}\text { User's } \\
\text { accuracy [\%] }\end{array}$ \\
\hline Agriculture land & 22 & 0 & 6 & 6 & 2 & 36 & 61.11 \\
\hline Barren land & 2 & 23 & 2 & 2 & 0 & 29 & 79.31 \\
\hline Built-up area & 4 & 7 & 22 & 5 & 1 & 39 & 56.41 \\
\hline Forest area & 2 & 0 & 0 & 17 & 2 & 21 & 80.95 \\
\hline Waterbody & 0 & 0 & 0 & 0 & 25 & 25 & 100.00 \\
\hline Total & 30 & 30 & 30 & 30 & 30 & 150 & - \\
\hline $\begin{array}{l}\text { Producer's } \\
\text { accuracy [\%] }\end{array}$ & 73.33 & 76.66 & 73.33 & 56.66 & 83.33 & - & - \\
\hline \multicolumn{8}{|c|}{ Overall accuracy: $72.66 \%$} \\
\hline \multicolumn{8}{|c|}{ Kappa coefficient: 0.65} \\
\hline
\end{tabular}


Table 4. Object-based classification confusion matrix

\begin{tabular}{|c|c|c|c|c|c|c|c|}
\hline \multirow[b]{2}{*}{ Classified data } & \multicolumn{7}{|c|}{ Reference data } \\
\hline & $\begin{array}{l}\text { Agriculture } \\
\text { land }\end{array}$ & $\begin{array}{l}\text { Barren } \\
\text { land }\end{array}$ & $\begin{array}{c}\text { Built-up } \\
\text { area }\end{array}$ & $\begin{array}{c}\text { Forest } \\
\text { area }\end{array}$ & Waterbody & Total & $\begin{array}{c}\text { User's } \\
\text { accuracy [\%] }\end{array}$ \\
\hline Agriculture land & 27 & 1 & 3 & 2 & 1 & 34 & 79.41 \\
\hline Barren land & 0 & 25 & 1 & 0 & 0 & 26 & 96.15 \\
\hline Built-up area & 0 & 4 & 26 & 5 & 0 & 35 & 74.28 \\
\hline Forest area & 2 & 0 & 0 & 23 & 3 & 28 & 82.14 \\
\hline Waterbody & 1 & 0 & 0 & 0 & 26 & 27 & 96.29 \\
\hline Total & 30 & 30 & 30 & 30 & 30 & 150 & - \\
\hline $\begin{array}{l}\text { Producer's } \\
\text { accuracy [\%] }\end{array}$ & 90.00 & 83.33 & 86.66 & 76.66 & 86.66 & - & - \\
\hline \multicolumn{8}{|c|}{ Overall accuracy: $84.66 \%$} \\
\hline \multicolumn{8}{|c|}{ Kappa coefficient: 0.80} \\
\hline
\end{tabular}

The OBC technique had an overall accuracy of $84.66 \%$, which was clearly higher than the pixel-based classification technique, which had an overall accuracy of $72.66 \%$ based on the overall accuracies of the confusion matrixes. As a result, we can conclude that OBC outperforms PBC.

A further step was to assess the accuracy of the producer's users and overall accuracy, as well as the kappa coefficient, which measures commission and omission errors of every land cover category. The confusion matrix's diagonal shows the correctly identified training pixels of land use/land cover categories, while the non-diagonal parts show errors of commission and omission. Non-diagonal column elements (Tab. 3), pixels that should have been classed as agriculture land were omitted from that class) were omitted due to omission errors. Commission errors, on the other hand, were associated with non-diagonal row elements (Tab. 3), agriculture land pixels were incorrectly included in the barren land category). When compared to producer accuracy, the OBC for agriculture land categories shows $90 \%$ accuracy, however, the PBC shows only $73.33 \%$, which is quite low when compared to OBC.

In comparison to all other categories, $\mathrm{OBC}$ had a higher producer accuracy than PBC (Fig. 7). In the pixel-based classification, user accuracy was better in the waterbody class; otherwise, object-based classification had superior accuracy in the remaining LULC categories (Fig. 8). Furthermore, the overall kappa accuracy in the $\mathrm{OBC}$ technique was larger than the PBC technique (Tabs. 3, 4), with 0.80 in the OBC and 0.65 in the PBC.

According to the outcomes of these two classification systems, the OBC technique had an advantage over the $\mathrm{PBC}$ technique in that it allowed for the integration of spatial and spectral information into a classification, which enhanced accuracy. 
It began with the segmentation procedure, which involved the creation of objects based on spatial and spectral data. Once objects were produced, classification became more vigorous since all pixels of the object were automatically categorized to the same class, resulting in a classification result that was closer to human visualization [5, 27]. However, object-based classification outperforms pixel-based classification.

\section{Producer's Accuracy}

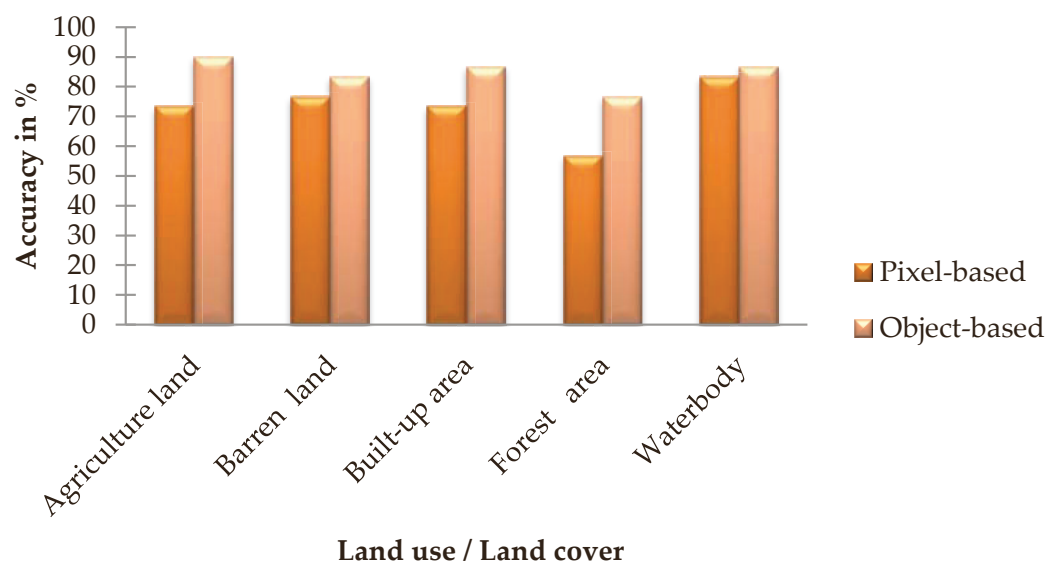

Fig. 7. Producer's accuracy of the pixel- and object-based classified image

\section{User's Accuracy}

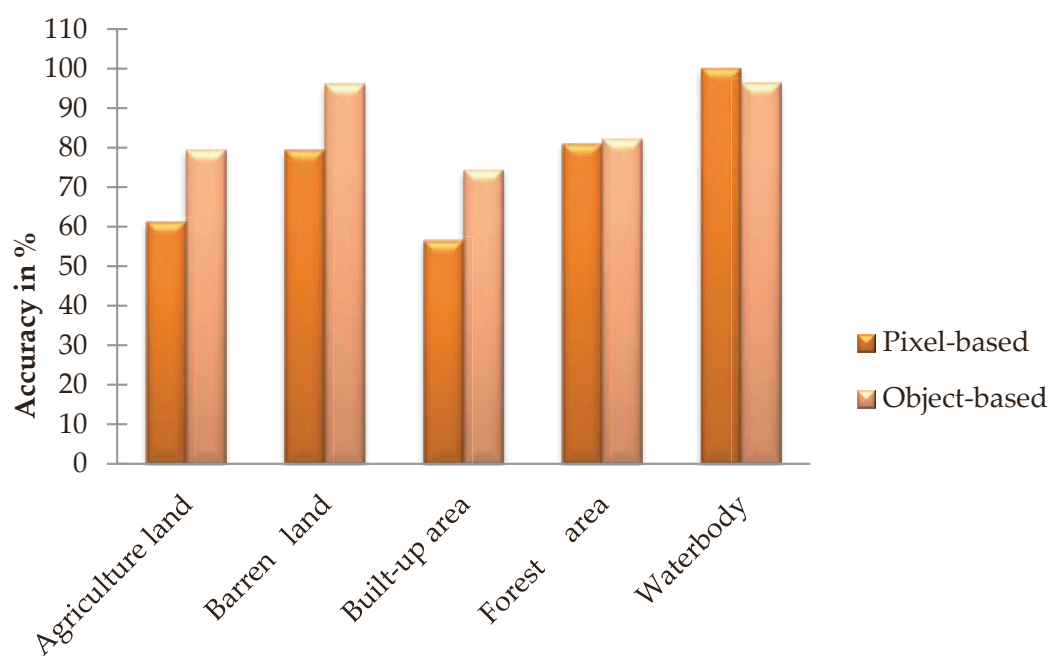

Land use / Land cover

Fig. 8. User's accuracy of the pixel- and object-based classified image 


\section{Conclusion}

The performance of two classification strategies, pixel-based and object-based classification, was tested in this research. Using the same image on the same target area, an accuracy assessment was carried out to evaluate the accuracy of these two procedures. In OBC, the overall classification accuracy was $84.66 \%$, while in PBC, it was $72.66 \%$. Furthermore, the object-based classification's total kappa accuracy was 0.80 , which was higher than the PBC (0.65). The object-based classification beat the pixel-based classification, according to the findings. In the OBC technique, the user and producer accuracy for most of the land-cover classifications was likewise good. Overall, the results show that the OBC method differentiates basic land use/ land cover types better, and the multi-resolution segmentation method, which was used to extract the segments needed for land feature classification, is also effective. This OBC technique is superior for high as well as medium resolution satellite images using this technique; one can easily do the image processing and extract the relevant land use land cover feature. The findings of this study show that OBC is more appropriate for high-resolution Resourcesat-2 satellite data than (MLC) PBC in terms of overall performance. Overall, the object-based map created in this study was smoother than the pixel-based MLC map, with larger, continuous classified areas and no single pixels classified differently from adjacent pixels, resulting in a saltand-pepper texture, as compared to the MLC map.

\section{References}

[1] Khan G.A., Khan S.A., Zafar N.A., Islam S., Ahmad F., Rehman M., Ullah M.: A review of different approaches of land cover mapping. Life Science Journal, vol. 9, 2012, pp. 1023-1032.

[2] Rajan K., Shibasaki R.: A GIS based integrated land use/cover change model to study agricultural and urban land use changes. Paper presented at the $22^{\text {nd }}$ Asian Conference on Remote Sensing, 5-9 November 2001, Singapore.

[3] Memarian H., Balasundram S.K., Khosla R.: Comparison between pixel- and object-based image classification of a tropical landscape using Système Pour observation de la Terre-5 imagery. International Journal of Applied Remote Sensing, vol. 7, 2013, 073512. https://doi.org/10.1117/1.JRS.7.073512.

[4] Ouattara T., Gwyn Q.H.J., Dubois J.-M.M.: Evaluation of the runoff potential in high relief semi-arid regions using remote sensing data: application to Bolivia. International Journal of Remote Sensing, vol. 25, 2004, pp. 423-435. https:// doi.org/10.1080/0143116031000102421.

[5] Gao Y., Mas J.-F., Maathuis B.H.P., Zhang X., van Dijk P.M.: Comparison of pixel-based and object-based image classification approaches - a case study in a coal fire area, Wuda, Inner Mongolia, China. International Journal of Remote Sensing, vol. 27(18), 2006, pp. 4039-4055. https://doi.org/10.1080/01431160600702632. 
[6] Enderle D., Weih R.C., Jr.: Integrating supervised and unsupervised classification methods to develop a more accurate land cover classification. Journal of the Arkansas Academy of Science, vol. 59, 2005, pp. 65-73. https://scholarworks.uark. edu/jaas/vol59/iss1/10.

[7] Zhou Q., Robson M.: Automated rangeland vegetation cover and density estimation using ground digital images and a spectral-contextual classifier. International Journal of Remote Sensing, vol. 22, 2001, pp. 3457-3470. https://doi.org/ 10.1080/01431160010004504.

[8] Pizzolato Angelo N., Haertel V.: On the application of Gabor filtering in supervised image classification. International Journal of Remote Sensing, vol. 24, 2003, pp. 2167-2189. https://doi.org/10.1080/01431160210163146.

[9] Campagnolo M.L., Cerdeira J.O.: Contextual classification of remotely sensed images with integer linear programming. [in:] Tavares J.M.R.S., Natal Jorge R.M. (eds.), Computational Modelling of Objects Represented in Images: Fundamentals, Methods, and Applications: Proceedings of the International Symposium CompIMAGE 2006 (Coimbra, Portugal, 20-21 October 2006), Taylor \& Francis, London 2007, pp. 123-128.

[10] Gao Y., Mas J.F.: A comparison of the performance of pixel-based and object-based classifications over images with various spatial resolutions. [in:] Hay G.J., Blaschke T., Marceau D. (eds.), GEOBIA 2008 - Pixels, Objects, Intelligence: GEOgraphic Object Based Image Analysis for the 21st Century, August 5-8, 2008, Calgary, Alberta, Canada, ISPRS Archives, vol. XXXVIII-4/C1, pp. 1-6.

[11] Van de Voorde T., De Genst W., Canters F., Stephenne N., Wolff E., Binard M.: Extraction of land use/land coverrelated information from very high resolution data in urban and suburban areas. [in:] Goossens R. (ed.), Remote Sensing in Transition: Proceedings of the 23rd EARSeL Symposium, Ghent, Belgium 2003, Millpress Science Publishers, Rotterdam 2004, pp. 237-244.

[12] Blaschke T.: Object-based image analysis for remote sensing. ISPRS Journal of Photogrammetry and Remote Sensing, vol. 65(1), 2010, pp. 2-16. https:// doi.org/10.1016/j.isprsjprs.2009.06.004.

[13] Baatz M., Schäpe A.: Multi-resolution segmentation: Anoptimization approach for high quality multi-scale segmentation. [in:] Strobl J., Blaschke T., Griesebner G. (Hrsg.), Angewandte geographische Informationsverarbeitung XII: Beiträge zum AGIT-Symposium Salzburg 2000, Wichmann, Heidelberg 2000, pp. 12-23.

[14] Blaschke T., Hay G.J., Kelly M., Lang S., Hofmann P., Addink E., Feitosa R.Q., van der Meer F., van der Werff H., van Coillie F., Tiede D.: Geographic objectbased image analysis - towards a new paradigm. ISPRS Journal of Photogrammetry and Remote Sensing, vol. 87, 2014. pp. 180-191. https://doi.org/10.1016/ j.isprsjprs.2013.09.014.

[15] Martha T.R., Kerle N., Jetten J., van Westen C.J., Vinod Kumar K.: Characterising spectral, spatial and morphometric properties of landslides for semi-automatic detection using object-oriented methods. Geomorphology, vol. 116, 2010, pp. 24-36. https://doi.org/10.1016/j.geomorph.2009.10.004. 
[16] Stumpf A., Kerle N.: Object-oriented mapping of landslides using Random Forests. Remote Sensing of Environment, vol. 115, 2011, pp. 2564-2577. https:// doi.org/10.1016/j.rse.2011.05.013.

[17] Holbling D., Füreder P., Antolini F., Cigna F., Casagli N., Lang S.: A semiautomated object-based approach for landslide detection validated by persistent scatterer interferometry measures and landslide inventories. Remote Sensing, vol. 4, 2012, pp. 1310-1336. https://doi.org/10.3390/rs4051310.

[18] Kurtz C., Stumpf A., Malet J.P., Gançarski P., Puissant A., Passat N.: Hierarchical extraction of landslides from multiresolution remotely sensed optical images. ISPRS Journal of Photogrammetry and Remote Sensing, vol. 87, 2014, pp. 122-136. https://doi.org/10.1016/j.isprsjprs.2013.11.003.

[19] Shackelford A.K., Davis C.H.: A combined fuzzy pixel-based and object-based approach for classification of high-resolution multispectral data over urban areas. IEEE Transactions on Geoscience and Remote Sensing, vol. 41, 2003, pp. 2354-2364. https://doi.org/10.1109/TGRS.2003.815972.

[20] Cambell J.B., Wynne R.H.: Introduction to Remote Sensing-Accuracy Assessment. $5^{\text {th }}$ ed. The Guilford Press, New York - London 2011.

[21] Dean A.M., Smith G.M.: An evaluation of per-parcel land cover mapping using maximum likelihood class probabilities. International Journal of Remote Sensing, vol. 24(14), 2003, pp. 2905-2920. https://doi.org/10.1080/01431160210155910.

[22] Rahman M.R., Saha S.K.: Multi-resolution Segmentation for Object-based Classification and Accuracy Assessment of Land Use/Land Cover Classification Using Remotely Sensed Data. Journal of the Indian Society of Remote Sensing, vol. 36, 2008, pp. 189-201. https://doi.org/10.1007/s12524-008-0020-4.

[23] Mather P.: Computer Processing of Remotely-Sensed Images: An Introduction. Wiley, Chichester 1999.

[24] Blaschke T., Strobl J.: What's wrong with pixels? Some recent development interfacing remote sensing and GIS. GIS - Zeitschrift für Geoinformationssysteme, vol. 14(6), 2001, pp. 12-17.

[25] Verbyla D.L.: Practical GIS Analysis. Taylor \& Francis, London - New York 2002.

[26] Jensen J.R.: Introductory Digital Image Processing: A Remote Sensing Perspective. Prentice Hall, New Jersey 1996.

[27] Giada S., De Groeve T., Ehrlich D., Soille P.: Information extraction from very high resolution satellite imagery over Lukole refugee camp, Tanzania. International Journal of Remote Sensing, vol. 24, 2003, pp. 4251-4266. https://doi.org/ 10.1080/0143116021000035021. 